Volume 5

\title{
To Look or Not to Look: Acknowledging Facial Stigmas in the Interview to Reduce Discrimination
}

Juan M. Madera

University of Houston

Mikki Hebl

Rice University

Follow this and additional works at: https://scholarworks.bgsu.edu/pad

Part of the Human Resources Management Commons, Industrial and Organizational Psychology Commons, and the Other Psychology Commons

How does access to this work benefit you? Let us know!

\section{Recommended Citation}

Madera, Juan M. and Hebl, Mikki (2019) "To Look or Not to Look: Acknowledging Facial Stigmas in the Interview to Reduce Discrimination," Personnel Assessment and Decisions: Number 5 : Iss. 2 , Article 3. DOI: https://doi.org/10.25035/pad.2019.02.003

Available at: https://scholarworks.bgsu.edu/pad/vol5/iss2/3

This Main Article is brought to you for free and open access by the Journals at ScholarWorks@BGSU. It has been accepted for inclusion in Personnel Assessment and Decisions by an authorized editor of ScholarWorks@BGSU. 


\title{
To LOOK OR Not to LOOK: ACKNOWLEDGING Facial Stigmas in the Interview to Reduce DISCRIMINATION
}

\author{
Juan M. Madera' and Mikki Hebl ${ }^{2}$
}

\author{
1. University of Houston \\ 2. Rice University
}

\begin{abstract}
As the use of technology-mediated interviews (e.g., Skype) is becoming a standard method to interview applicants, it is important to understand how discrimination can still manifest in these types of interviews. Because technology-mediated interviews focus on applicants' faces, discrimination based on facial stigmas can be particularly inevitable. Thus, the purpose of the current study is to examine how a facial stigma affects visual attention during a technology-mediated interview and acknowledgment as a remediation strategy that individuals might use to reduce the amount of visual attention on a facial stigma. We used a 2 (acknowledge: yes or no) x 2 (target gender: male or female) experimental design. The participants heard a computer-mediated interview while viewing one of the manipulated images. For half of the conditions, the participants heard the applicant acknowledge their stigma. Using an eye tracker, visual attention to the stigma was measured every 30 seconds during the 8-minute interview, producing 16 different time points and a total of 1,792 data points. Multilevel growth curve model analysis examined variation in the trajectory of visual attention to the stigma. The results showed that facial stigmas draw visual attention during a computer-mediated interview, which decreased over time. However, the trajectory of the decrease in visual attention depended on whether an applicant acknowledged their stigma during the interview. The decrease in visual attention was faster in the acknowledgment condition than in the control condition. The current research provides a better understanding to how a facial stigma influences the interview process and provides a theoretical rationale for why acknowledging a facial stigma benefits the interview process.
\end{abstract}

Technology-mediated interviews are becoming a popular method of conducting selection interviews (Behrend \& Thompson, 2013; Horn \& Behrend, 2017). Technology-mediated interviews use cutting edge video-based interviewing platforms, such as Skype, GoToMeeting, Webex, and Adobe Connect, which allow employers to streamline selection and hiring activities, process an increasingly larger pool of potential candidates, interview geographically distant applicants, and reduce the costs of onsite visits (Blacksmith, Willford, \& Behrend, 2016). Although this method is different from the face-to-face method because the interviewer is not physically present with the applicant, the technology-mediated interview does share many common elements with the traditional, face-to-face interview. For example, an interviewer can see the applicants from mid-chest up and therefore have a clear picture of an applicant's face (Horn $\&$ Behrend, 2017). Any physical anomalies on the face of an applicant would still be visible and therefore potentially biasing. In fact, research shows that individuals who have facial stigmas can face varying forms of discrimination in the employment interview (Buijsrogge, Derous, \& Duyck, 2014; Buijsrogge, Derous, \& Duyck, 2016; Derous, Buijsrogge, Roulin, \& Duyck, 2016; Madera \& Hebl, 2012).

One way that facial stigmas can negatively impact an employment interview is that it draws visual attention, potentially distracting the interviewer from the content. People will often stare at a facial stigma in an attempt to understand them because facial anomalies and/or deformities are unexpected when meeting a person (Bonanno \& Esmaeli, 2012; Madera, 2016; Stone \& Wright, 2012;

Corresponding author:

Juan M. Madera

4450 University Drive, Room 227

Houston, TX 77204

Email:jmmadera@uh.edu 
Wali \& Regmi, 2016). However, staring at a facial stigma is related to negative affective and attitudinal responses from stigmatized individuals (Halioua, Williams, Murray, Skalko, \& Vogelsong, 2011; Masnari et al., 2012). Research also shows that because nonstigmatized individuals often feel uncomfortable, awkward, and anxious when interacting with stigmatized individuals, stigmatized individuals are aware of the negative reactions that their stigma elicits in others (Hebl, Tickle, \& Heatherton, 2000; Major \& O'Brien, 2005). For example, people with facial paralysis will often use expressive hand gestures and expressive voice to compensate for their lack of facial expressions (Bogart, Tickle-Degnen, \& Joffe, 2012). Goffman (1963) noted that stigmatized individuals are aware that their stigma elicits negative reactions, such as staring, and therefore tend to engage in stigma management to reduce their own and perceivers' attention, discomfort, and/or anxiety.

Staring at a stigma not only increases the uneasiness the stigmatized individual and/or interaction partner has about the interaction but also affects attention given to the content of the interview. In a study of computer-mediated interviews, Madera and Hebl (2012) found that applicants with facial stigmas were rated lower on overall effectiveness than applicants without a facial stigma. More importantly, they found that staring at a stigma led participants to recall fewer interview information, which in turn led to lower applicant ratings. Therefore, a reason why a facially stigmatized applicant was evaluated negatively was due to the distraction that a facial stigma creates.

Thus, the literature shows that the visual attention paid to a stigma in an interview is fundamental. Despite this reality, strategies that applicants can use to attempt to reduce visual attention toward a stigma in the interview process has been largely ignored. Therefore, the purpose of the current study is to examine how a facial stigma affects visual attention during a technology-mediated interview and a remediation strategy that individuals might use to reduce the amount of visual attention on a facial stigma. In doing so, we expand upon the findings from Madera and Hebl (2012) in two ways. First, we used visual attention measured over time to examine how visual attention is directed to and away a facial stigma during a computer-mediated interview. Second, we examined the role of acknowledgment as an identity management strategy that can help reduce the level of visual attention given to a stigma. This study draws from theory and research on perceived stigma (Pryor, Reeder, Yeadon, \& Hesson-McInnis, 2004) and attentional processes (Rinck \& Becker, 2006). Pryor et al. (2004) proposed a theoretical model of individual psychological reactions to perceived stigma, in which reactions to stigma involve a reflexive, automatic system that draws attention. When individuals are confronted with a stigmatized applicant (e.g., a birth mark on his/her face) individuals might be more likely to focus their attention to the stigma while trying to focus on the interview responses. Acknowledgment might be beneficial by providing an explanation for the stigma, releasing the interviewer from staring at it.

\section{Literature Review}

\section{Facial Stigmas and Reactions}

In his influential book on stigma, Goffman (1963) defined stigma as an attribute that discredits individuals and prevents an individual from full social acceptance. Goffman further specified that stigmas can be characterized as: (a) moral flaws, (b) physical aberrations of the body, or (c) heredity-based factors. Stigmas can also vary in the degree to which they are perceived to be controllable. For example, the stigmas of being a drug addict, having AIDS, being homeless, or homosexuality are more likely to be perceived to be controllable than the stigmas of race and age.

When interacting with stigmatized individuals, people often experience feelings of discomfort, anxiety, and threat during social interactions (for a review see Hebl, Madera, \& King, 2007; and Madera \& Hebl, 2013). Research shows that facial disfigurements, such as scars and port-wine stains (i.e., nevus flammeus), are particularly pernicious and universal stigmas (Blascovich, Mendes, Hunter, Lickel, \& Kowai-Bell, 2002; Stone \& Potton, 2014, 2017), because face perception (i.e., how people process a face) is an effortless but highly developed skill in people that serves different communicative functions in social interaction, such as person identification and recognition (Li \& Jain, 2005). In addition, starting in infancy, people have an innate tendency to allocate visual attention to faces (Li \& Jain, 2005). In fact, evidence suggests that facial disfigurements are processed and recognized by newborns (Cohen, 1998; Johnson, Dziurawiec, Ellis, \& Morton, 1991).

Therefore, facial stigmas are highly discernible and salient for face processing. Because face perception also appears to depend upon distinct brain areas that relies on different special processes than other stimuli (Li \& Jain, 2005; McKone, Kanwisher, \& Duchaine, 2007; Tsao, Moeller, \& Freiwald, 2008), facial disfigurements may be a "hardwired" stigma (Hebl et al., 2000; Johnson et al., 1991). For example, Blascovich et al. (2002) used physiological measures to examine the extent to which perceivers feel anxiety and threat during interactions with stigmatized individuals. Participants interacted with individuals without or with a stigma, manipulated by using makeup to create a facial stigma. Results showed that interacting with confederates with a facial stigma increased cardiovascular activity.

Research suggests that people tend to visually attend to negative or threatening stimuli when presented with both positive and negative stimuli (Fox, Russo, Bowles, \& Dutton, 2001). Certain stigmas, like facial disfigurements, are often feared because they are perceived to be contagious, a threating source for perceivers (Major \& O'Brien, 2005). 
Some researchers have argued from an evolutionary perspective that, at an early stage of information processing, visual attention is particularly sensitive to biologically relevant and threatening stimuli, which automatically commands visual attention (Fox et al., 2001; Rinck \& Becker, 2006). That is, visual attention is biased selectively toward threatening stimuli. Thus, threatening stimuli may be particularly salient regions that capture visual attention.

Facial stigmas can signal a perceived flaw or abnormality related to work-related characteristics, such as personality flaws, mental illnesses, or competency (Schumacher, Corrigan, \& Dejong, 2003; Summers, Howe, McElory, Buckley, Phang, \& Cortes-Mejia, 2018). For example, physical attractiveness, which is negatively affected by facial stigmas (Thompson \& Kent, 2001), is often associated with being more intelligent, competent, and successful (Eagly, Ashmore, Makhijani, \& Longo, 1991; Summers et al., 2018). Therefore, it is also possible that a facial stigma draws visual attention in an interview context because of what it can signal about the applicant.

Alternatively, other research suggests that the need to look at a facial stigma is not only because it is perceived as negative, but because it is novel. Coined as the "novel stimulus" hypothesis, people who have physical stigmas are "novel" and therefore are stared at more in an attempt to make them less novel (Langer, Fiske, Taylor, \& Chanowitz, 1976; Thompson \& Kent, 2001). That is, people stare at a facial stigma because facial disfigurements are unexpected but not necessarily perceived negatively. Regardless if a facial stigma is perceived to be a threat, signals work-related characteristics, or novel or a combination of these reasons, research suggests that people allocate visual attention to stigmas on the face.

\section{Facial Stigmas in the Interview Context}

Technology-mediated interviews can be cognitively taxing in that they require interviewers to assess applicants, gain information about applicants, sell their organization, and make important decisions while trying not be distracted by the picture of the applicant's face on the video (Horn \& Behrend, 2017). At the same time, interviewers might also be concerned with how they appear to applicants, especially in situations in which the applicant has a facial stigma (e.g., port-wine stain; Buijsrogge et al., 2016). Stigmatized individuals elicit perceivers to feel discomfort, anxiety, and threat (Blascovich et al., 2002), and people often stare at a facial stigma in formal and casual interactions (Bonanno \& Esmaeli, 2012; Masnari et al., 2012; Madera, 2016; Wali \& Regmi, 2016).

Using eye tracker methodology, Madera and Hebl (2012) examined potential discrimination against facially stigmatized applicants in computer mediated interviews. In the first study, participants viewed the face of an applicant (with or without a facial stigma) while listening to the inter- view and rated the applicant's performance. To investigate the underlying process involved in the discrimination, visual attention toward the stigma was measured. The results showed that the memory of interview facts was negatively impacted by visual attention directed to the stigma, which in turn resulted in lower applicant ratings. In Study 2, the authors used face-to-face interviews and replicated the findings that a facial stigma distracts from the interview content, which results in lower ratings for the applicants. Thus, in a technology-mediated interview, a facial stigma will command visual attention, but, how visual attention changes over the course of the interview has not been examined.

Models by Mathews and Mackintosh (1998), Mogg et al. (2000), and Rinck and Becker (2006) suggest that that there are two phases that explain the process how a facial stigma will command visual attention and change over time. The first phase is automatic in that people tend to quickly and automatically attend to threatening stimuli. The second phase is a slower, cognitively controlled process, which involves assessing the significance of the stimuli, which often involves coping behaviors. Coping behaviors include keeping their focus of attention on the threatening stimuli, disengaging visual attention, or quickly avoiding them (Fox et al., 2001; Hermans, Vansteenwegen, \& Elen, 1999; Rinck \& Becker, 2006).

These models suggest that in a computer-mediated interview, visual attention to the stigma will be an automatic reaction. This first phase is not rationale or based on logic but on automatic impulses to stare at stimuli that can be threatening, signal other characteristics, or are novel like a facial stigma. For example, in a study of visual attention to facial stigmas (port wine stain), participants looked at faces with or without facial stigmas on a computer (Ackerman et al., 2009). Results showed that participants looked at faces with facial stigmas longer than faces without the stigma. This effect was stronger when the participants were primed with a disease threat (i.e., they read about contagious diseases). Thus, even when they are not physically in the presence of a stigmatized person, the automatic reaction to a facial stigma is to stare.

These models of visual attention toward threatening stimuli overlap with models of reactions toward stigmas. In fact, the stigma model proposed and tested by Pryor et al. (2004) also suggests a dual process in which the first phase is automatic (i.e., an instinctive or spontaneous negative reaction toward the stigma) and the second phase is also a controlled reaction in which people reflect on whether they should or should not avoid the stigmatized individual. These theories suggest that when individuals are confronted with a stigmatized individual (e.g., a port-wine stain on their face), individuals might be more likely to focus their visual attention to the features of the stigma but then also try to control (i.e., avoid looking at the stigma) their visual attention. These theories also suggest that perceivers will 
eventually look less at the stigma. Thus, the features of a physical stigma can be distracting, commanding attention as they are unexpected, provoking attributional analyses (e.g., why does he/she have that?) that then lead to coping strategies to look away (e.g., Mathews \& Mackintosh, 1998; Mogg et al., 2000; Pryor et al., 2004; Rinck \& Becker; 2006). In an interview context, a facial stigma will draw visual attention, and this visual attention will decrease over time as the perceiver becomes accustomed to it. More formally:

Hypothesis 1: There will be a gradual decrease in the amount of visual attention to a facial stigma over time during an interview.

\section{Acknowledgment of Stigmas}

Although there are empirical and theoretical reasons to hypothesize that stigmas will draw attention in interview contexts, there is research that shows that stigmatized individuals can proactively remediate potential negative reactions from perceivers. In fact, Goffman (1963) noted that stigmatized individuals tend to engage in stigma management. One such strategy is controlling the potential negative reaction from perceivers by disclosing or acknowledging (i.e., act of directly referring to one's stigma during an interaction).

Evidence suggests that interactions with stigmatized individuals can be uncomfortable and negative for non-stigmatized individuals (Blascovich et al., 2002; Hebl et al, 2000; Krendl, Macrae, Kelley, Fugelsang, \& Heatherton, 2006). Acknowledgment can be an effective strategy because it may reduce the preoccupation with the fear of saying something inappropriate about the target. For example, acknowledgment may release the perceivers from a state of anxiety, threat, thought suppression or other self-regulatory behaviors, which would otherwise use limited resources (Macrae, Bodenhousen, Milne, \& Jetten, 1994; Monteith, Sherman, \& Devine, 1998).

Acknowledgment can also reduce negative feelings toward stigmatized individuals. In one of the earliest known studies on acknowledgment, Davis (1961) found that when an individual made explicit statements about his or her physical disability, nonstigmatized individuals were less likely to view the disabled individual with disdain, pity, and contempt. Research has also demonstrated that the positive effect of acknowledgment can depend on a number of factors (Hebl \& Kleck, 2002; Hebl \& Skorinko, 2005). For instance, Hebl and Kleck (2002) found that perceived controllability moderated the effect of acknowledgment on ratings of an applicant. In the first study, participants responded to a videotaped interview involving an obese or physically disabled job applicant who either did or did not acknowledge a stigma. In the second study, participants responded to scenarios that manipulated type of stigma, controllability of its onset, and acknowledgment. Results across both experiments reveal that applicants who did not acknowledge their stigma in an employment context were viewed and rated similarly. However, if applicants did acknowledge, the perceived controllability of the stigmas strongly influenced how they would be perceived by the participants in that perceived controllability was related to lower ratings.

Similarly, research demonstrates a temporal effect of acknowledgment (Hebl \& Skorinko, 2005). Participants responded to a videotaped interview of a disabled applicant who made no acknowledgment about the disability or who acknowledged the disability at the beginning, middle, or end of a job interview. Applicants who did not acknowledge or who acknowledged at the end of the interview were rated less favorably than were those who disclosed earlier in the interview. Furthermore, the results showed that happy/well-adjusted perceptions mediated the effect. Thus, stigmatized individuals might positively control the impression-formation process by acknowledging early in the interview.

We theorize that acknowledgment might be beneficial if it draws focus on the stigma, but then it makes it less novel by providing an explanation. One possibility is that acknowledgment releases interviewers from the potential anxiety and threat of staring at the stigma. Another possible mechanism is that without acknowledgment, interviewers might look more at the stigma because they think about why and how the stigma occurred. Regardless of the mechanism, we hypothesized a time course of acknowledgment. Specifically, acknowledgment will initially direct more attention to the stigma, but an acknowledgment provides an explanation (i.e., birthmark), which influences the visual attention toward the stigma as time progresses. According to models of stigmatization (Pryor et al., 2004; Weiner, Perry, \& Magnusson, 1988), individuals engage in sophisticated assessments when confronted with a stigmatized individual that involve adjustments, such as what to feel, how to behave toward the target, and attributions of controllability, contagion, and onset. By interrupting such assessments of stigmatized individuals, acknowledgment will lead to less visual attention as time progresses. By providing an explanation for the facial stigma, perceivers will stare less because they will not be preoccupied thinking about what, why, how, or when the stigma was produced.

In the absence of acknowledgment, the features of the stigma will continue to draw attention as time progresses because individuals engage in assessments of the target. Thus, we expected more visual attention during the time of acknowledgment but then a decrease of attention in the following time points, whereas there will be a slower decrease in the amount of visual attention in the absence of acknowledgment. That is, attention to the stigma will decrease with time as the stigma on the face becomes less novel, but this 
decrease will be significantly more after acknowledgment than in the absence of acknowledgment. More formally:

Hypothesis 2: There will be a significant effect of acknowledgment on visual attention to a facial stigma, such that the decrease of visual attention to a stigma will decrease faster when an applicant acknowledges their stigma than when an applicant does not acknowledge their stigma.

\section{METHOD}

\section{Participants}

We used data collected and reported by Madera and Hebl (2012) and analyzed data that have not been previously reported. Participants were 112 (39 male and 73 female) undergraduate students who participated in exchange for experimental credit. They had an average age of 19.6 (SD $=1.4)$. The majority identified as Caucasian $(n=49)$, followed by Asian $(n=32)$, Latino(a) $(n=14)$, Black/African-American $(n=15)$, and "other" $(n=6)$.

\section{Design and Procedure}

We used a 2 (acknowledge: yes or no) x 2 (target gender: male or female) factorial design with visual attention to the stigma as the outcome, measured every 30 seconds during the 8-minute interview. We manipulated applicant gender for generalizability and exploratory reasons. We instructed the participants to review a computer-mediated interview in which they viewed a picture of an applicant on a computer screen while listening to an interview wherein the applicant detailed his/her work experience. We positioned the participants in front of the computer and informed them that their visual attention would be tracked and recorded throughout the study to ostensibly study how the lighting and resolution of the computer screen can affect attention, thereby explaining the use of an eye tracker. The images of the applicant faces - taken from the same camera under the same conditions and resolution-were created by the MIT-CBCL face recognition database (Weyrauch, Heisele, Huang, \& Blanz, 2004). To address possible idiosyncratic differences in the type of facial stigma, we used two types of facial stigmas: port-wine stain (i.e., nevus flammeus) or scar.

The participants then heard a computer-mediated interview while viewing one of the four manipulated images (i.e., male with a port-wine stain or a scar, female with a port-wine stain or a scar). For half of the conditions, the participants heard the applicant acknowledge their stigma within the first minute of the interview, in which the applicant described a challenge they had faced. Specifically, the applicant acknowledged, "I have had this (["birthmark" for port-wine stain condition] or ["scar"]) on my face since birth, but I don't let it get in the way" For the nonacknowl- edgment conditions, this acknowledgment was not included. After the interview, the participants completed a questionnaire that included demographic measures.

\section{Measures}

Visual attention. To assess visual attention toward the stigma, we created a measure of the percent of time looking at the stigma. Visual attention to the stigma was measured for every 30 seconds during the 8-minute interview, producing 16 different time points and a total of 1,792 data points from the 112 participants. The average percent of time spent visually attending the stigma, across the 16 time points, was $10.10 \%(S D=0.12)$.

\section{RESULTS}

Because the visual attention data were nested within participants, we used multilevel growth curve models to test the hypotheses. Multilevel growth curve models analysis examines variation in the trajectory of visual attention to the stigma for each participant. We used linear mixed models in SPSS Statistics 24 to conduct these analyses. This approach of analysis has several advantages over traditional methods (i.e., repeated measures analysis of variance) to examine change over time, such as having less stringent assumptions, handling missing data, and addressing the hierarchical structure of the data (Shek \& Ma, 2011).

We first estimated the unconditional model with no predictors (Model 1) to assess between-participants variation in visual attention. This model addresses the average visual attention to the facial stigma for participants and if the participants' visual attention to the stigma varied between participants. The intraclass correlation (ICC) was 0.14 , which suggests that $14 \%$ of the variance in visual attention existed between participants.

As shown in Table 1, in Model 2, we added the level-1 predictor of time (i.e., visual attention was measured 16 times across the 8-minute interview) to examine the unconditional linear growth model. The intercept of an unconditional linear growth model is the average value on the outcome being examined at the first time point. Thus, the average visual attention at the beginning of the interview was 0.14 , and it is statistically significant, suggesting that in the first 30 seconds, participants spent $14 \%$ of their visual attention to the stigma versus other features of the face. The parameter estimate for the time variable represents the average visual attention decrease over time. The results of this model provide an estimate of the impact of time, which had a fixed effect value of -0.005 and is statistically significant. With every time point that passed, on average, participants' visual attention to the stigma decreased by $0.50 \%$. Thus, the results supported Hypothesis 1, that there would be a gradual decrease in the amount of visual attention to a facial stigma over time. Specifying time as a random effect, 
the results also suggest that the decrease in visual attention varied between participants.

Before examining the effect of acknowledgment on visual attention to a facial stigma, we examined a model (Model 3) that included two fixed effects level-2 predictors we manipulated - the applicant gender and the type of stig$\mathrm{ma}$ - and their interaction with time to examine if the visual attention to a facial stigma over time varied by applicant gender and the type of stigma. The results showed that the applicant gender and the type of stigma did not affect the trajectory of visual attention over time to the facial stigma.

Model 4 added acknowledgment as a fixed effect level-2 predictor of visual attention to the stigma and the interaction effect of acknowledgment and time. Acknowledgment was not associated with the initial status of visual attention $(\beta=0.014, p>0.05)$, suggesting that there were no statistical difference between the acknowledgment and nonacknowledgment conditions in visual attention to the stigma during the first 30 seconds. However, supporting Hypothesis 2, the results showed that acknowledgment was a significant predictor of the linear trajectory of visual attention $(\beta=-0.003, p<0.05)$, suggesting that the decrease trajectory in the visual attention to the stigma varied between the acknowledgment and nonacknowledgment conditions.

Figure 1 shows the decrease trajectory of visual attention to the stigma by acknowledgment. We examined the decrease trajectory of visual attention to the stigma in each acknowledgment condition. In the nonacknowledgment condition, the fixed effect value of time was -0.0033 , suggesting that with every time point that passed, on average, participants visual attention to the stigma decreased by $0.33 \%$. The intercept was 0.135 , suggesting that the average visual attention to the stigma at the beginning of the interview was $13.5 \%$. Thus, the average overall decrease of visual attention to the stigma for the nonacknowledgment condition was $4.8 \%$ from $13.5 \%$. In the acknowledgment condition, the fixed effect value of time was -0.0063 , suggesting that with every time point that passed, on average, participants visual attention to the stigma decreased by

TABLE 1.

Estimates for a Two-Level Growth Model Examining Visual Attention to a Facial Stigma

\begin{tabular}{|c|c|c|c|c|}
\hline & Model 1 & Model 2 & Model 3 & Model 4 \\
\hline \multicolumn{5}{|l|}{ Fixed Effects } \\
\hline Intercept & $0.10(0.004)^{*}$ & $0.14(0.008)^{*}$ & $0.12(0.027)^{*}$ & $0.07(0.06)$ \\
\hline Time & & $-0.005(0.001)^{*}$ & $-0.005(0.001)^{*}$ & $0.004(0.004)$ \\
\hline Applicant gender & & & $-0.004(0.009)$ & $0.017(0.015)$ \\
\hline Type of stigma & & & $0.007(0.009)$ & $0.003(0.016)$ \\
\hline Acknowledgment & & & & $0.014(0.016)$ \\
\hline Time*Applicant Gender & & & $-0.002(0.001)$ & $-0.002(0.001)$ \\
\hline Time*Type of Stigma & & & $0.001(0.001)$ & $0.0003(0.001)$ \\
\hline Time*Acknowledgment & & & & $-0.003(0.001)^{*}$ \\
\hline \multicolumn{5}{|l|}{$\begin{array}{l}\text { Variance of random } \\
\text { components }\end{array}$} \\
\hline Intercept & $0.002(.0004)^{*}$ & $0.004(0.001)^{*}$ & $0.004(0.001)^{*}$ & $0.004(0.001)^{*}$ \\
\hline Slope & & $0.00002(0.00001)^{*}$ & $0.00002(0.00001)^{*}$ & $0.00001(0.00001)^{*}$ \\
\hline Covariance & & $-0.0002(0.0001)^{*}$ & $-0.0002(0.0001)^{*}$ & $-0.0002(0.0001)^{*}$ \\
\hline \multicolumn{5}{|l|}{ Model fit } \\
\hline AIC & -2719.59 & -2875.73 & -2832.83 & -2827.56 \\
\hline BIC & -2703.13 & -2771.45 & -2690.92 & -2679.83 \\
\hline
\end{tabular}

Note. ICC $=0.14$. Standard errors are shown in parentheses. Estimation method $=$ REML. ${ }^{*} p<0.05$. 
$0.63 \%$. The intercept was 0.148 , suggesting that the average visual attention to the stigma at the beginning of the interview was $14.8 \%$. Thus, the average overall decrease of visual attention to the stigma for the acknowledgment condition was $9.6 \%$ from $14.8 \%$.

These results supported Hypothesis 2 that there would be a significant effect of acknowledgment on visual attention to a facial stigma, such that the decrease of visual attention to a stigma will decrease faster when an applicant acknowledges their stigma than when an applicant does not acknowledge their stigma. In sum, the average overall decrease of visual attention to the stigma for the acknowledgment condition was $9.6 \%$ versus $4.8 \%$ for the nonacknowledgment condition.

\section{DISCUSSION}

As the use of technology-mediated interviews is becoming a standard method to interview applicants, it is important to understand how discrimination can still manifest in these types of interviews. Because technology-mediated interviews focus on applicants' faces, discrimination based on facial stigmas can be particularly inevitable. In fact, a growing body of literature shows that individuals who have facial stigmas often receive varying forms of discrimination in the employment interview (Buijsrogge et al., 2014; Buijsrogge et al., 2016; Derous et al., 2016). For example, Madera and Hebl (2012) found that applicants with facial stigmas were rated lower on overall effectiveness than ap- plicants without a facial stigma and that this bias was due to the visual distraction that a facial stigma creates. To expand upon the findings from Madera and Hebl (2012), we used visual attention measured over time to examine how visual attention fluctuates during a computer mediated interview. We also examined the role of acknowledgment as an identity management strategy that can help reduce the level of visual attention given to a stigma.

The results showed that facial stigmas do indeed draw visual attention during a computer-mediated interview. Research shows that when looking at faces, people tend to fixate on the internal region of the face: the eyes, nose, and mouth (Mertens, Siegmund, \& Grusser, 1993; Rayner, 1998; Stacey, Walker, \& Underwood, 2005). The current study found that participants spent $16 \%$ of visual attention on the eyes, $13 \%$ on the nose, and $7 \%$ on the mouth. These results suggest that a facial stigma interrupts the "normal" face processing pattern by commanding as much attention as the "normal" regions of the face (i.e., eyes, mouth, and nose).

In addition, the results showed that visual attention toward a visual stigma decreases over time. However, the trajectory of the decrease in visual attention depended on whether an applicant acknowledges their stigma during the interview. The decrease in visual attention was faster in the acknowledgment condition, whereas it was slower when the applicant did not acknowledge the stigma. Last, these results did not vary by the applicant's gender nor by the type of stigma (i.e., scar or port-wine stain). By reducing visual

FIGURE 1.

Trajectory of visual attention to the stigma by acknowledgment.

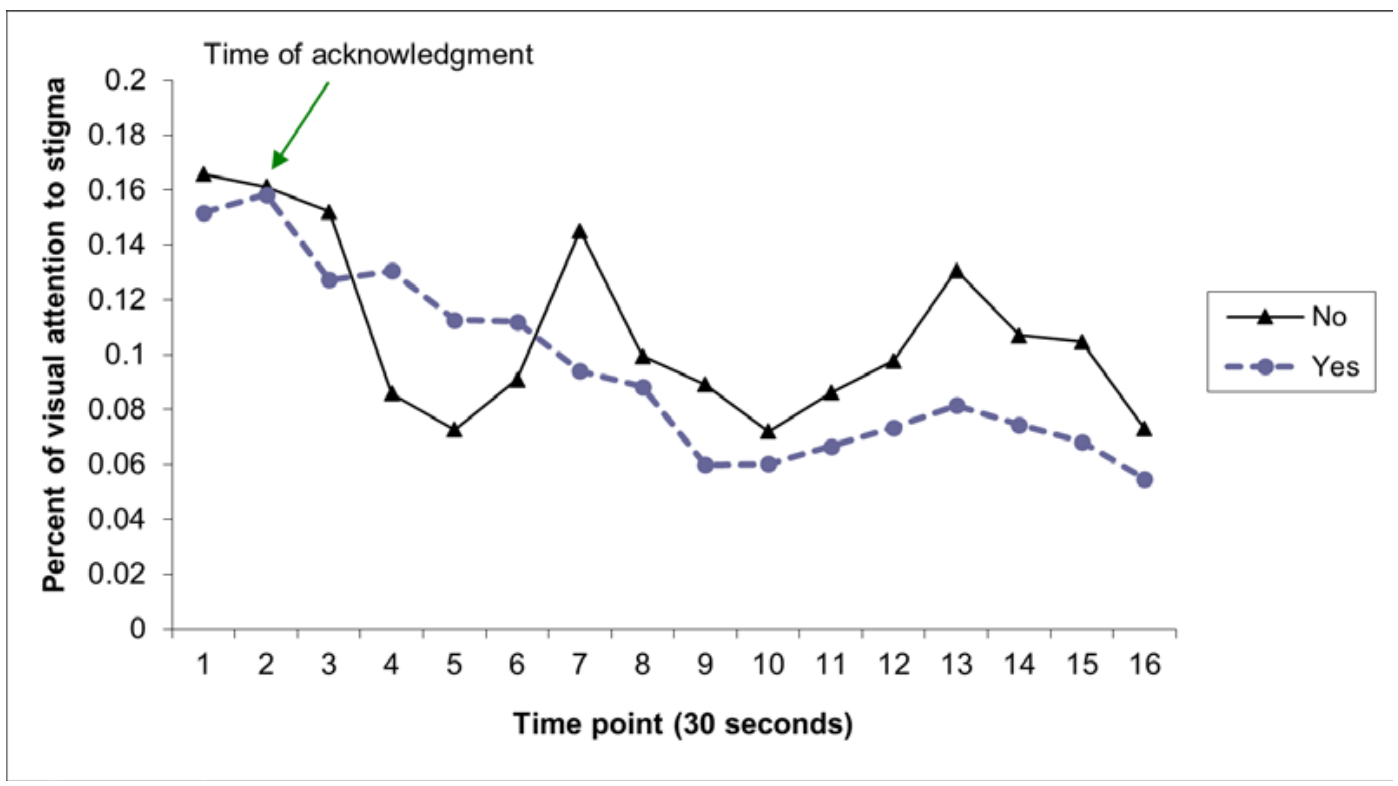


attention to a facial stigma, acknowledgment potentially leads to more attention to relevant information in the interview, which is related to better recall and applicant evaluation as shown by Madera and Hebl (2012).

\section{Theoretical Implications}

By using the time-based component of visual attention to a stigma not used in Madera and Hebl (2012), the current research provides a better understanding to how a facial stigma influences the interview process. The stigma model proposed and tested by Pryor et al. (2004) provides a theoretical framework to understand these results. Accordingly, perceiving a stigma involves a dual process in which the first phase is automatic (e.g., staring at the stigma) and the second phase is a controlled reaction in which people reflect on whether they should or should not avoid the stigmatized individual. The results showed that participants stared at the facial stigma during the interview and that visual attention fluctuates during the interview, slowly decreasing over time. These results suggest that participants controlled or monitored their visual attention to stare less at the stigma.

The results of the current study also provide a theoretical rationale for why acknowledging a facial stigma can benefit the interview process. We theorized and found that acknowledgment would reduce visual attention because it can make the stigma less novel by providing an explanation. Acknowledgment releases interviewers from the need to stare at the stigma to think about what it is. Without acknowledgment, interviewers might look more at the stigma because they think about it (e.g., why they have a facial deformity, how it occurred, when it occurred). We found that the by providing an explanation (i.e., birthmark or scar since birth) in the acknowledgment condition, visual attention toward the stigma reduced faster than in the nonacknowledgment condition. According to models of stigmatization (Pryor et al., 2004; Weiner et al., 1988), when confronted with a stigmatized individual, perceivers often think about the stigma, but by interrupting such assessments of stigmatized individuals, acknowledgment led to less visual attention over time. Therefore, this study provides evidence that acknowledgment can serve as an effective identity management strategy by reducing the level of visual attention paid to a stigma. This evidence is particularly important given the fact that Madera and Hebl (2012) found that the discrimination against applicants with facial stigmas was due to the visual distraction that a facial stigma creates during an interview.

\section{Practical Implications}

The results offer practical implications for both organizations conducting computer-mediated interviews and applicants with facial stigmas. For applicants with stigmas, acknowledgment can serve as an effective strategy to draw attention away from the stigma and decrease attention over time faster than not acknowledging the stigma. The current results suggest that acknowledgment potentially draws attention away from the stigma and back to the relevant information in the interview, which is important in evaluating applicants (Madera \& Hebl, 2012). Acknowledgment may also reduce the uneasiness the stigmatized individual and/ or interaction partner has about the interaction (Blascovich et al., 2002; Hebl et al, 2000; Krendl et al., 2006). When individuals are confronted with a stigmatized applicant, they often focus their attention to the stigma, which can be uncomfortable and distracting. Thus, acknowledgment can be beneficial by providing an explanation for the stigma.

Second, because the results suggest facial stigmas do indeed draw visual attention, video-based interviewing should be structured. Our current research shows the importance of drawing attention away to the stigma. Structured interviews might draw the interviewers' attention to the interview items and ratings and away from a stigma.

Another implication from the current study is that technology-based interviews should be conducted blindly by not using video-based interviewing platforms (e.g., Skype, GoToMeeting, and Adobe Connect). Although it is impossible to keep the entire selection process blind, technology-based interviews are often the first hurdle that applicants must pass. Keeping this blind can prevent any potential bias that a stigma can present before they are given the opportunity for an onsite interview. This is particularly important because stigmatized individuals are often aware when other individuals stare at their facial stigma (Halioua et al., 2011; Masnari et al., 2012). Applicants who perceive bias or discrimination in an interview can lead to negative reactions toward the hiring organization. That is, applicants also use the selection interview to evaluate the organization (Rynes \& Cable, 2003), and organizational attractiveness is negatively affected when applicants perceive unfair treatment, such as perceived bias or discrimination (Truxillo, Steiner, \& Gilliland, 2004). Perceiving unfair treatment in the selection process is also related to legal complaining (Smither, Reilly, Millsap, Pearlman, \& Stoffey, 1993). Legal complaining is particularly important because certain facial and skin conditions may be covered under the American with Disabilities Act (ADA). Recent amendments to the ADA protects applicants who are treated as though they have a disability, regardless if their stigma is actually a disability or not under the ADA (Segal, 2010). Thus, reducing discrimination against applicants with facial stigmas in technology-mediated interviews should be taken seriously.

\section{Limitations and Future Research}

Using an eye tracker was a strength of the current study because it measures visual attention over time. However, this also presents a potential limitation, namely, the participants did not actually interact the applicant by asking the interview questions. Future research might examine physi- 
cal stigmas in the interviews using live interactions and use videos to record facial reactions (although it would not be able to record visual attention) because people might possibly react differently when interacting with facially stigmatized applicants. Social norms suggest that it is not civil to stare at others, particularly when the target of gaze has a physical stigma, but people also struggle to stare because of the novelty of a stigma (Langer et al., 1976; Thompson, 1982). In the current study, we believe (and found evidence) that people were restricting their eye movements because third parties (i.e., the experimenter and camera) were watching them. In a live interaction, people are likely restricting their eye movements because their interactant is watching them. What we cannot ascertain from the current research is how similar these two situations are. It is possible that face-to-face interactions might involve increased social pressures for the nonstigmatized individual to not stare or to look away from the stigma.

In addition, the interview information was positive, suggesting that the applicant was a strong candidate. Future research can investigate how manipulating interview responses (e.g., strong, average, or poor) can influence the effect of a facial stigma and acknowledgment on visual attention. For example, the justification-suppression model of prejudice (Crandall \& Eshelman, 2003) suggests that individuals are more likely to show bias and discrimination against stigmatized individuals when given justifications, such as information that confirms negative stereotypes of stigmatized others.

Last, we outlined three potential reasons for why a facial stigma can draw visual attention, namely, because it can be threatening, it can signal work-related characteristics, or it is novel. It might also be a combination of these reasons. Future research might examine the role these possible reasons play in the visual attention given to a facial stigma. For example, these reasons can be primed to examine difference in the amount of visual attention given to facial stigmas.

\section{REFERENCES}

Ackerman, J. M., Becker, D. V., Mortensen, C. R., Sasaki, T., Neuberg, S. L., \& Kenrick, D. T. (2009). A pox on the mind: Disjunction of attention and memory in the processing of physical disfigurement. Journal of Experimental Social Psychology, 45(3), 478-485.

Behrend, T.S., \& Thompson, L.F. (2013). Combining I-O psychology and technology for an environmentally sustainable world. In A. H. Huffman \& S. R. Klein (Eds.) Green organizations: Driving change with I-O psychology (pp. 300-322). New York, NY: Routledge.

Blacksmith, N., Willford, J. C., \& Behrend, T. S. (2016). Technology in the employment interview: A meta-analysis and future research agenda. Personnel Assessment and Decisions, 2(1), 12-20.

Blascovich, J., Mendes, W. B., Hunter, S. B., Lickel, B., \& Kowai-Bell, N. (2002). Perceiver threat in social interactions with stigmatized others. Journal of Personality and Social Psychology, 80, 253-267.

Bogart, K. R., Tickle-Degnen, L., \& Joffe, M. S. (2012). Social interaction experiences of adults with Moebius Syndrome: A focus group. Journal of Health Psychology, 17(8), 1212-1222.

Bonanno, A., \& Esmaeli, B. (2012). Cancer and facial disfigurement: Reducing survivors' stigma in social interaction. Clinical Journal of Oncology Nursing, 16(2), 153.

Buijsrogge, A., Derous, E., \& Duyck, W. (2014). You are in control: Investigating the effect of stigma controllability on interview outcome. Academy of Management Proceedings, 2014(1), 10768.

Buijsrogge, A., Derous, E., \& Duyck, W. (2016). Often biased but rarely in doubt: How initial reactions to stigmatized applicants affect interviewer confidence. Human Performance, 29(4), 275-290.

Cohen, L. B. (1998). An information-processing approach to infant perception and cognition. In F. Simion \& G. Butterworth (Eds.), The development of sensory, motor, and cognitive capacities in early infancy: From perception to cognition (pp. 277-300). East Sussex, UK: Psychology Press.

Crandall, C.S., \& Eshleman, A. (2003). A justification-suppression model of the expression and experience of prejudice. Psychological Bulletin, 129, 414-446.

Davis, F. (1961). Deviance disavowel: The management of strained interaction by the visibly handicapped. Social Problems, 9, 120-132.

Derous, E., Buijsrogge, A., Roulin, N., \& Duyck, W. (2016). Why your stigma isn't hired: A dual-process framework of interview bias. Human Resource Management Review, 26(2), 90111.

Eagly, A. H., Ashmore, R. D., Makhijani, M. G., \& Longo, L. C. (1991). What is beautiful is good, but...: A meta-analytic review of research on the physical attractiveness stereotype. Psychological Bulletin, 110(1), 109.

Fox, E., Russo, R., Bowles, R. J., \& Dutton K. (2001). Do negative stimuli draw or hold visual attention in subclinical anxiety? Journal of Experimental Psychology: General, 130, 681-700.

Goffman, E. (1963). Stigma: Notes on the management of spoiled identity. New York, NY: Prentice Hall.

Halioua, R. L., Williams, R. S., Murray, N. P., Skalko, T. K., \& Vogelsong, H. G. (2011). Staring and perceptions of people with facial disfigurement. Therapeutic Recreation Journal, 45(4), 341.

Hebl, M. R., \& Kleck, R. E. (2002). Acknowledging one's stigma in the interview setting: Effective strategy or liability? Journal of Applied Social Psychology, 32, 223-249.

Hebl, M. R., \& Skorinko, J. L. (2005). Acknowledging one's physical disability in the interview: Does "when" make a difference? Journal of Applied Social Psychology, 35(12), 2477-2492.

Hebl, M. R., Madera, J. M., \& King, E. B. (2007). Exclusion, avoidance, and social distancing. In K. M. Thomas (Ed.), Diversity resistance: Manifestation and solutions (pp. 127-150). Mahwah, NJ: Lawrence Erlbaum Associates. 
Hebl, M. R., Tickle, J., \& Heatherton, T. F. (2000). Awkward moments in interactions between nonstigmatized and stigmatized individuals. In T. Heatherton, R. Kleck, M. Hebl, \& J. Hull (Eds.), The social psychology of stigma. New York, NY: Guilford Press.

Hermans, D., Vansteenwegen, D., \& Elen, P. (1999). Eye movement registration as a continuous index of attention deployment: Data from a group of spider anxious students. Cognition and Emotion, 13, 419-434.

Horn, R. G., \& Behrend, T. S. (2017). Video killed the interview star: Does picture-in-picture affect interview performance?. Personnel Assessment and Decisions, 3(1), 51-59.

Johnson, M. H., Dziurawiec, S., Ellis, H. \& Morton, J. (1991). Newborns' preferential tracking of face-like stimuli and its subsequent decline. Cognition, 40, 1-19.

Krendl, A. C., Macrae, C. N., Kelley, W. M., Fugelsang, J. A., \& Heatherton, T. F. (2006). The good, the bad, and the ugly: An fMRI investigation of the functional anatomic correlates of stigma. Social Neuroscience, 1, 5-15.

Langer, E. J., Fiske, S., Taylor, S. E., \& Chanowitz, B. (1976). Stigma, staring, and discomfort: A novel-stimulus hypothesis. Journal of Experimental Social Psychology, 12, 451-463.

Li, S. Z., \& Jain, A. K. (2005). Handbook of face recognition. New York, NY: Springer Science.

Macrae, C. N., Bodenhausen, G. V., Milne, A. B., \& Jetten, J. (1994). Out of mind but back in sight stereotypes on the rebound. Journal of Personality and Social Psychology, 67, 808-818.

Madera, J. M. (2016). Facial stigmas in dyadic selection interviews: Affective and behavioral reactions toward a stigmatized applicant. Journal of Hospitality \& Tourism Research, 40(4), 456-475.

Madera, J. M., \& Hebl, M. R. (2012). Discrimination against facially stigmatized applicants in interviews: An eye-tracking and face-to-face investigation. Journal of Applied Psychology, 97(2), 317.

Madera, J. M., \& Hebl, M. R. (2013). Social exclusion of individuals through interpersonal discrimination. In C. N. DeWall (Ed.) Handbook of social exclusion (pp. 55-64). New York, NY: Oxford University Press.

Major, B., \& O'Brien, L. T. (2005). The social psychology of stigma. Annual Review of Psychology, 56, 393-421.

Masnari, O., Landolt, M. A., Roessler, J., Weingaertner, S. K., Neuhaus, K., Meuli, M., \& Schiestl, C. (2012). Self-and parent-perceived stigmatisation in children and adolescents with congenital or acquired facial differences. Journal of Plastic, Reconstructive \& Aesthetic Surgery, 65(12), 1664-1670.

Mathews, A., \& Mackintosh, B. (1998). A cognitive model of selective processing in anxiety. Cognitive Therapy and Research, 22, 539-560.

McKone, E., Kanwisher, N. K., \& Duchaine, B. C. (2007). Can genetic expertise explain special processing for faces? Trends in Cognitive Science, 11, 8-15.

Mertens, I., Siegmund, H., \& Grusser, O. (1993). Gaze motor asymmetries in the perception of faces during a memory task. Neuropsychologia, 31, 989-998.

Mogg, K., McNamara, J., Powys, M., Rawlinson, H., Seiffer, A., \& Bradley, B. P. (2000). Selective attention to threat: A test of two cognitive models of anxiety. Cognition \& Emotion, 14, 375-399.
Monteith, M. J., Sherman, J. W., \& Devine, P. G. (1998). Suppression as a stereotype control strategy. Personality and Social Psychology Review, 2, 63-82.

Pryor, J. B., Reeder, G. D., Yeadon, C., \& Hesson-McInnis, M. (2004). A dual process model of reactions to perceived stigma. Journal of Personality and Social Psychology. 87, 436-452.

Rayner, K. (1998). Eye movements in reading and information processing: 20 years of research. Psychological Bulletin, 124, 372-422.

Rinck, M., \& Becker, E.S. (2006). Spider fearful individuals attend to threat, then quickly avoid it: Evidence from eye movements. Journal of Abnormal Psychology, 115, 231-238.

Rynes, S. L., \& Cable, D. M. (2003). Recruitment research in the twenty first century. In W. C. Borman, D. R. Ilgen, \& R. J. Klimoski (Eds.), Handbook of psychology: Industrial and organizational psychology (Vol. 12, pp. 55-76). New York, NY: Wiley.

Schumacher, M., Corrigan, P. W., \& Dejong, T. (2003). Examining cues that signal mental illness stigma. Journal of Social and Clinical Psychology, 22(5), 467-476.

Segal, J. A. (2010). ADA game changer: Avoid 10 common mistakes in the reasonable accommodation process. HR Magazine, June 2010, 121-125.

Shek, D. T., \& Ma, C. (2011). Longitudinal data analyses using linear mixed models in SPSS: Concepts, procedures and illustrations. Scientific World Journal, 11, 42-76.

Smither, J. W., Reilly, R. R., Millsap, R. E., Pearlman, K., \& Stoffey, R. W., 1993. Applicant reactions to selection procedures. Personnel Psychology, 46, 49-77.

Stacey, P. C., Walker, S., \& Underwood, J. D. M. (2005). Face processing and familiarity: Evidence from eye-movement data. British Journal of Psychology, 96, 407-422.

Stone, A., \& Potton, A. (2014). Emotional responses to disfigured faces: The influences of perceived anonymity, empathy, and disgust sensitivity. Basic and Applied Social Ps y chol o gy, 36(6), 520-532.

Stone, A., \& Potton, A. (2017). Emotional responses to disfigured faces and disgust sensitivity: An eye-tracking study. Journal of Health Psychology, 24(9), 1191-1200.

Stone, A., \& Wright, T. (2012). Evaluations of people depicted with facial disfigurement compared to those with mobility impairment. Basic and Applied Social Psychology, 34(3), 212-225.

Summers, J. K., Howe, M., McElroy, J. C., Ronald Buckley, M., Pahng, P., \& Cortes-Mejia, S. (2018). A typology of stigma within organizations: Access and treatment effects. Journal of Organizational Behavior.

Thompson, T. L. (1982). Gaze toward and avoidance of the handicapped: A field experiment. Journal of Nonverbal Behavior, 6, 188-196.

Thompson, A., \& Kent, G. (2001). Adjusting to disfigurement: Processes involved in dealing with being visibly different. Clinical Psychology Review, 21, 665-682.

Truxillo, D. M., Steiner, D. D., \& Gilliland, S. W. (2004). The importance of organizational justice in personnel selection: Defining when selection fairness really matters. International Journal of Selection and Assessment, 12(1-2), 39-53.

Tsao, D. Y., Moeller, S., \& Freiwald, W. A. (2008). Comparing face patch systems in macaques and humans. Proceedings of 
the National Academy of Sciences, 105, 19514-19519.

Wali, I. M., \& Regmi, K. (2016). People living with facial disfigurement after having had noma disease: A systematic review of the literature. Journal of Health Psychology, 22(10), 12431255

Weiner, B., Perry, R. P., \& Magnusson, J. (1988). An attributional analysis of reactions to stigmas. Journal of Personality and Social Psychology, 55, 738-748.

Weyrauch, B., Heisele, B., Huang, J., \& Blanz, V. (2004, June). Component-based face recognition with 3D morphable models. In Computer Vision and Pattern Recognition Workshop, 2004.

RECEIVED 04/30/18 ACCEPTED 02/06/19 